S1 Table. Pha13-responsive differentially expressed genes (DEGs) compared to vector control are classified into NPR1-dependent and independent groups following previous studies.

\begin{tabular}{|c|c|c|c|c|c|c|}
\hline ID $^{\mathbf{a}}$ & Alias & Description & $\log ^{b} \quad$ P value & $\begin{array}{l}\text { Fold } \\
\text { changes }^{c}\end{array}$ & \multicolumn{2}{|c|}{ References } \\
\hline \multicolumn{7}{|c|}{ NPR1-dependent genes } \\
\hline PATC 145800 & WRKY70 & WRKY Transcription Factor & At3g56400 & 0.000010 & 14.11 & [53] \\
\hline PATC152659 & WRKY53 & WRKY Transcription Factor & At4g23810 & 0.000282 & 5.19 & [53] \\
\hline PATC139697 & $\begin{array}{l}\text { Protein } \\
\text { kinase }\end{array}$ & Protein kinase superfamily protein & At3g09010 & 0.013400 & 1.63 & [31] \\
\hline PATC148973 & APK $2 b$ & Protein kinase $2 \mathrm{~B}$ & At2g02800 & 0.014900 & 2.05 & [31] \\
\hline PATC141782 & YSL3 & YELLOW STRIPE like 3 & At5g53550 & 0.000426 & 3.11 & [31] \\
\hline PATC135791 & NPR1 & $\begin{array}{l}\text { Key regulator of the salicylic acid (SA)-mediated systemic } \\
\text { acquired resistance (SAR) pathway. }\end{array}$ & At1g64280 & 0.014900 & 1.61 & \\
\hline PATC154483 & & LisH and RanBPM domain-containing protein & AT1g61150 & 0.006653064 & 1.44 & [53] \\
\hline PATC133682 & LURP1 & $\begin{array}{l}\text { A member of the LURP cluster which exhibits pronounced } \\
\text { upregulation after recognition of the pathogenic oomycte } H \text {. } \\
\text { parasitica. }\end{array}$ & AT2g 14560 & 0.000362737 & 2.38 & [53] \\
\hline PATC142626 & CPFTSY & $\begin{array}{l}\text { Chloroplast SRP receptor homolog. Required for LHCP } \\
\text { integration into isolated thylakoids. }\end{array}$ & AT2g45770 & 0.04253212 & 1.38 & {$[53]$} \\
\hline
\end{tabular}




\section{S1 Table. Cont.}

\begin{tabular}{|c|c|c|c|c|c|c|}
\hline PATC154050 & & $\begin{array}{l}\text { Encodes an aspartic protease, has an important regulatory } \\
\text { function in chloroplasts. }\end{array}$ & AT3g12700 & 0.000322238 & 3.64 & {$[53]$} \\
\hline PATC 143146 & $\mathrm{RdR} 1$ & RNA-dependent RNA polymerase & At1g14790 & 0.031000 & 1.38 & \\
\hline \multicolumn{7}{|c|}{ NPR1-independent genes } \\
\hline PATC152473 & SSI2 & $\begin{array}{l}\text { A stearoyl-ACP desaturase, involved in fatty acid } \\
\text { desaturation }\end{array}$ & At2g43710 & 0.019400 & 1.34 & {$[54]$} \\
\hline PATC125646 & WRKY3 & WRKY DNA-binding protein 3 & At2g03340 & 0.001050 & 2.03 & {$[55]$} \\
\hline PATC129486 & WRKY21 & WRKY DNA-binding protein 21 & At2g30590 & 0.003180 & 1.57 & {$[55]$} \\
\hline PATC154824 & IEGT & UDP-glucosyl transferase 73B1 & AT4g34138 & 0.000117 & 2.32 & {$[56]$} \\
\hline PATC068819 & GRXC9 & $\begin{array}{l}\text { Encodes GRX480, a member of the glutaredoxin family } \\
\text { that regulates protein redox state }\end{array}$ & At1g28480 & 0.000002 & 15.04 & {$[57]$} \\
\hline PATC132182 & GRXS13 & $\begin{array}{l}\text { Glutaredoxin ATGRXS13, required to facilitate Botrytis } \\
\text { cinerea infection of Arabidopsis thaliana plants. }\end{array}$ & At1g03850 & 0.006730 & 1.9 & {$[57]$} \\
\hline PATC148347 & $\mathrm{ADH} 1$ & $\begin{array}{l}\text { Catalyzes the reduction of acetaldehyde using NADH as } \\
\text { reductant }\end{array}$ & At1g77120 & 0.002740 & 1.67 & [31] \\
\hline PATC225126 & DMR6 & $\begin{array}{l}\text { DOWNY MILDEW RESISTANT 6. Encodes a putative } \\
\text { 2OG-Fe(II) oxygenase that is defense-associated but } \\
\text { required for susceptibility to downy mildew }\end{array}$ & At5g24530 & 0.015500 & 2.06 & [31] \\
\hline
\end{tabular}




\section{S1 Table. Cont.}

\begin{tabular}{|c|c|c|c|c|c|c|}
\hline PATC143725 & ASPGB1 & $\begin{array}{l}\text { Encodes an asparaginase that catalyzes the } \\
\text { degradation of L-asparagine to L-aspartic acid and } \\
\text { ammonia. }\end{array}$ & At3g16150 & 0.001380 & 3.23 & {$[53]$} \\
\hline PATC139952 & ATAPR3 & $\begin{array}{l}\text { A member of a multigene family within the } \\
\text { thioredoxin (TRX) superfamily. }\end{array}$ & At4g21990 & 0.000346 & 3.47 & [31] \\
\hline PATC156665 & ANAC002 & $\begin{array}{l}\text { A member of the NAC family of transcription } \\
\text { factors }\end{array}$ & At1g01720 & 0.000008 & 6.48 & [31] \\
\hline PATC127565 & AOX & $\begin{array}{l}\text { The alternative oxidase of plant mitochondria } \\
\text { transfers electrons from the ubiquinone pool to } \\
\text { oxygen without energy conservations }\end{array}$ & At3g22370 & 0.039800 & 1.25 & {$[53]$} \\
\hline
\end{tabular}

${ }^{a}$ Accession number of Orchidstra database (http://orchidstra.abrc.sinica.edu.tw)

${ }^{\mathrm{b}}$ Accession number of TAIR (http://www.Arabidopsis.org)

${ }^{\mathrm{c}}$ All DEGs are selected based on significance (unpaired t test $P<0.05$ ) 